\title{
A CONTRIBUIÇÃO PEIRCIANA PARA A REPRESENTAÇÃO INDEXAL DE IMAGENS VISUAIS ${ }^{1}$
}

\author{
THE PERCIEN CONTRIBUTION FOR AN INDEXAL REPRESENTATION \\ OF VISUAL IMAGES
}

\begin{abstract}
Virginia Bentes Pinto ${ }^{2}$ - vbentes@ufc.br, virginia.bentes@pesquisador.cnpq.br Dra. Ciências da Informação e da Comunicação - Univ. Sténdhal Grenoble-3 - França

Lider do Grupo de Pesquisa Representação da Informação Professora do Depto. de Ciências da Informação da Universidade Federal do Ceará Jean-Guy Meunier - meunier.jean-guy@uqam.ca Diretor do Lab. de l'Analyse Cognitve de l'Information (LANCI) Université du Quebec à Montreal Professor do Depto. de Filosofia da Université du Quebec à Montreal Casemiro Silva Neto - casemironeto@bol.com.br Dr. Comunicação e Cultura-Universidade Federal do Rio de Janeiro Vice-Lider do Grupo de Pesquisa Representação da Informação Professor do Depto. de Ciências da Informação da Universidade Federal do Ceará
\end{abstract}

\begin{abstract}
Resumo
Mesmo que ao longo da história as imagens visuais tenham adquirido enorme importância, como fontes de informação, não é possível negar que, com as novíssimas ferramentas da informação e da comunicação (TIC), elas ganharam a atenção de estudiosos dos mais variados campos do conhecimento, representados pelas artes, biologia, astronomia, arqueologia, história, saúde, moda, decoração, publicidade, editoração, engenharia e arquitetura, dentre outros. Apresenta algumas reflexões teóricas concernentes à representação na perspectiva peirciana, ancorando-se no contexto das novas formas de abordagem empregadas para o tratamento de imagens visuais, utilizando como exemplos os paradigmas da representação indexal manual, semi-automática, automática e mista. Os resultados das experimentações mostram que as dificuldades encontradas na construção de uma representação indexal, desse tipo de documento, decorrem da complexidade inerente ao processo de produção e recepção do signo imagético.
\end{abstract}

Palavras-Chave: Imagem. Representação indexal de imagem. Representação sígnica de imagens.

\footnotetext{
${ }^{1}$ Artigo baseado em Relatório de Pesquisa Referente à Estágio Pós-Doutoral em Filosofia- Análise Cognitiva da Informação -Université du Québec à Montreal- Laboratoire de l'Analyse Cognitive de l'Information (LANCI).

${ }^{2}$ Agradeço à Coordenação de Pessoal de Nível Superior(CAPES) pelo apoio.
} 


\section{INTRODUÇÃO}

L'image en tant que telle n'est pas une catastrophe récente, mais au contraire un bien précieux inséparable de ce qui construit l'humanité, car elle est solidaire de la parole et de la pensée". (Mondzain, 2003, p.17-18)

A epígrafe apresentada como abertura deste artigo enuncia que a importância e demandas das imagens não cessam de crescer ao longo da história, legitimando-se nos domínios científico, técnico, histórico, artístico e econômico, dentre outros. $\mathrm{Na}$ área de história, as imagens são documentos de grande valor para a construção ou reconstrução dos fatos históricos; nas organizações, elas podem ser empregadas como dispositivos da memória organizacional, favorecendo o reconhecimento de assinaturas e impressões digitais etc. No contexto da saúde, desde a invenção do raio-X, pelo físico Wilhelm Konrad Röntgen, no final dos anos 1895, as imagens revolucionam as investigações e, igualmente, as formas de trabalho. Neste sentido, elas favorecem e asseguram a confiabilidade nos diagnósticos de certas doenças; servem como fontes de informação no planejamento e orientação de tratamentos; subsidiam investigações acerca do estado e evolução das doenças; além de funcionarem como meios para o ensino e divulgação dos conhecimentos. Rudolf Arnheim (1969 apud AUMONT, 1990, p.56) escreve que as imagens possuem relação direta com o mundo real, pois elas assumem ao menos três valores: a) de representação, onde figuram as coisas concretas - imagem de um pulmão; b) de símbolo, onde figuram as coisas abstratas; o vinho representando o sangue de Cristo para os católicos; c) de signo, onde o conteúdo que nelas figura não reflete visualmente seus caracteres e cuja significação visual é arbitrária em relação ao seu significado - se o sinal é vermelho, a gente pára. Para Barboza (1997, p.7), a imagem oscila entre a sua "verdade material, que não é unicamente gráfica, e o mistério, o que ela representa; ela é uma janela aberta sobre outras variedades, dissimulada através do gesto humano e criador. É que a imagem, a exemplo da técnica, é uma criação especificamente humana".

Bentes Pinto e Meunier (2006, p. 85) argumentam que a importância dos documentos imagéticos na sociedade contemporânea é tão grande, que não podemos explicar, compreender, ou nos reportar a certos assuntos sem o testemunho das imagens. É o caso de algumas doenças, da fome no mundo, dos assaltos e roubos, das mudanças da biosfera, da violência urbana, da degradação do meio ambiente, e das conseqüências das guerras em grande parte do Planeta. Por isso, observa-se também o uso deliberado das imagens ditas funcionais, em vários domínios de conhecimento: principalmente na pedagogia, comunicação, astrofísica etc. Contudo, se, por um lado, a imagem conquistou tamanha importância com os dispositivos digitais e eletrônicos possibilitando combinar texto verbal (palavra) e não-verbal (som, imagem) num mesmo documento multimidiático, por outro, impõe sérias dificuldades. E a razão disso é porque, depois da explosão bibliográfica, estamos vivendo outra explosão documental ainda mais avassaladora, que é a explosão ou excesso das imagens visuais, cujo enfrentamento reivindica outras modalidades metodológicas, teóricas e conceituais de lidar com esse material. 
No âmbito das atividades referidas neste trabalho, as imagens, à semelhança do que acontece com os textos verbais, também podem e precisam ser indexadas, porém o procedimento há que ser diferente, a fim de que o acesso ao seu conteúdo seja menos problemático. Afinal, pela própria natureza, a imagem é um documento constituído de vários outros textos, dentre os quais podemos citar, pelo menos, a cor, a forma e a textura. Face à complexidade das dimensões semânticas desse universo sígnico, foi que nos interessamos em estudar a representação indexal de imagens visuais seguindo a trajetória construída pela semiótica peirciana.

\section{ALGUNS OLHARES E DIZERES SOBRE REPRESENTAÇÃO}

\subsection{A concepção peirciana de representação}

O significado que a palavra representação encerra não é de origem tão recente, conforme parecem imaginar alguns. Muito pelo contrário, ela sempre esteve presente no espírito humano, pelo menos, desde a Pré-história quando os homens primitivos, em suas práticas cotidianas, buscavam possibilidades de comunicação através da criação de imagens ou ideogramas; assim como da escrita cuneiforme dos sumérios e dos hieróglifos produzidos no Antigo Egito.

Na semiótica peirciana, é o signo que desencadeia a representação, uma vez que ele é percebido como sendo "[...] algo que, sob certo aspecto ou de algum modo, representa alguma coisa para alguém" (PEIRCE, CP7, p.357). Neste sentido, entendemos que, se na representação o signo está em lugar de outra coisa, isto significa que não há uma relação causal entre tal signo e sua representação, mas, antes de tudo, uma relação significativa para alguém que constrói outras representações e, assim, sucessivamente. Entretanto, Peirce não se contenta com este conceito inicial de signo. Por isso, propõe outro mais complexo:

Signo ou representamen é aquilo que, sob certo aspecto ou modo, representa algo para alguém. Dirige-se a alguém, isto é, cria, no espírito dessa pessoa, um signo equivalente, ou talvez um signo mais desenvolvido. Ao signo assim criado denomino interpretante do primeiro signo. O signo representa alguma coisa, seu objeto. Representa esse objeto não em todos os seus aspectos, mas com referência a um tipo de idéia que eu, por vezes, denominei fundamento do representamen. (PEIRCE, CP 2, p.228).

Nesta passagem, percebe-se, inicialmente, que a existência de um signo ou representamen exige a presença de, ao menos, três elementos: o signo mesmo, o objeto (representante deste signo) e o interpretante (efeito, idéia ou toque) para que ele possa se fazer signo. Deste modo, o signo apresenta-se de maneira dinâmica em razão da própria dinamicidade do ser humano, logo, enquanto representação, ele não diz respeito apenas a "estar no lugar de qualquer coisa", porém estabelece relações sígnicas entre as referidas coisas. O representamen, enquanto veículo do signo, "é o sujeito de uma relação triádica, com um segundo chamado seu objeto, para um terceiro chamado seu interpretante" e que possibilita sempre o nascimento de um novo signo (interpretante), e, assim, sucessivamente, ou seja, sempre uma nova construção sígnica, demonstrando assim, a "infiniteza" (infinitude) do signo. Daí porque a este processo Peirce denomina de "semiosis ilimitada". Sua estrutura sígnica (signo, objeto, interpretante) proposta por Peirce(1907, CP.5. p. 484), é construída em forma de triângulo semiótico denominado 
"semiosis" enquanto interpretação de signos e que envolve "uma ação ou influência que é ou implica numa cooperação de três sujeitos, um signo, seu objeto e seu interpretante, de tal modo que essa influência tri-relativa de modo algum se pode resolver sem que haja ações entre pares". Em outras palavras a "semiosis" diz respeito à ação apreensiva do signo.

No conceito de representação defendido por Peirce, percebe-se que o sentido desta palavra diz respeito à ação de colocar diante dos olhos ou diante do espírito de alguém uma produção de sentidos, uma construção formada pela reunião de três outras palavras "re", "present" e "ação", e que nos leva a pensar ao menos em três outras possibilidades: a existência da coisa ou objeto ("present"), a mobilização do sujeito que se apropria deste objeto ou coisa ("ção") e a representação desta apropriação que se constituirá em uma "presença nova" (Meunier, 2002) do objeto enunciado através do prefixo ("re"). Não é a presença do objeto em si mesmo que lhe confere o estatuto de sua representação, mas, sobretudo, a presença de uma idéia (consciência interpretativa) do indivíduo sensível que age sobre esta coisa ou sobre este objeto, lhe conferindo sentida a fim de produzir uma representação concernente a esta coisa ou este objeto que ele percebe no mundo. Se tomarmos como modelo o termo banana, enquanto um objeto do mundo, real ou simbólico, ele pode também ser representado através das várias imagens, e pode ser percebido com inúmeras possibilidades, por exemplo, a fruta, $\mathrm{o}$ artefato para se brincar na água a tomada etc. conforme a figura 1

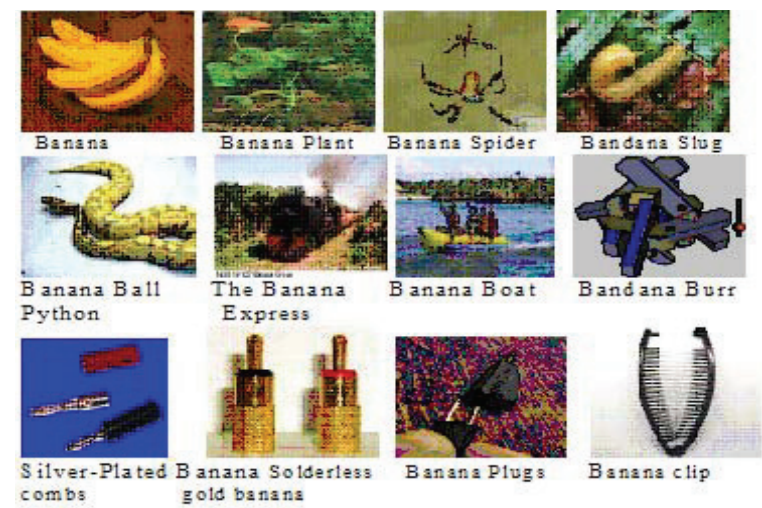

Fig. 1- Polissemia de representação indexal da imagem Fonte : http://www.google.com/

As imagens apresentadas na figura 1 mostram claramente que é o interpretante mesmo, enquanto signo mental, que favorece a mediação entre um signo e um outro signo, pois, como bem diz Peirce (1999, p. 46) "um signo somente pode ser signo a partir do momento que possa se traduzir em um outro signo no qual ele aparece completamente desenvolvido". O mesmo acontece com a imagem de um "neurônio", por exemplo, trata-se de um signo (representamen) que está no lugar de um objeto (neurônio mesmo). Porém ele somente pode ser signo, "à la Peirce", se for capaz de gerar no interpretante outro signo mais evoluído. A possibilidade de acesso ao neurônio real somente é possível se formos especialistas do domínio da anatomia e fisiologia, e abrirmos alguma parte do corpo humano ou animal para efeitos de cirurgia, em caso contrário, tal acesso dar-se-á através da representação imagética. Mas, este signo nos leva a um interpretante (idéia sobre o objeto) que, por sua vez, pode ser concernente a um conceito da biologia ou do contexto das ciências cognitivas, entre outros. Segundo Thürlemann (1990, apud 
SANTAELLA e Nöth, 1999, p. 25-31) e Edeline et al. (1992) esta imagem também pode criar outros interpretantes, através de outros, componentes visuais denominados de elementos abstratos ou plásticos da imagem (cores ou formas), contrastes cromáticos (comparando-se cores, plano e não-pleno) e categorias eidéticas (quadrado comparado com redondo, côncavo com convexo). Todos estes elementos possuem valor semântico próprio para compor a estrutura de composição da imagem dando sentido, não apenas estético, porém de conteúdos semânticos (figura 2).

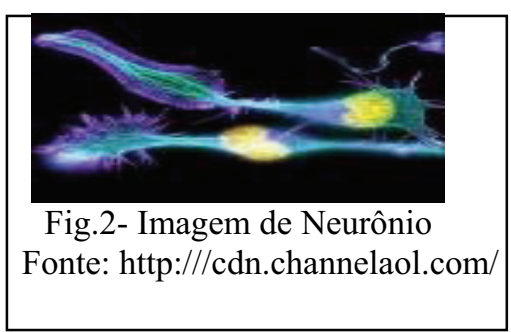

Pode-se ainda representar o neurônio por intermédio da equação matemática proposta por McCulloch e Pitts nos anos 1943 e mostrada na figura 3.

$$
\begin{aligned}
& \mathrm{y}=\mathrm{f}\left(\sum^{\mathrm{n}} \mathrm{W}_{\mathrm{i}} \mathrm{x}_{\mathrm{i}}-\mathrm{b}\right)=\mathrm{f}\left(\mathbf{W}^{\mathrm{t}} \mathbf{x}-\mathrm{b}\right) \\
& \text { Fig.3- Fórmu1a matemáticado neuronio } \\
& \text { Fonte: http://ww w - vnix.ecs.umass.edu }
\end{aligned}
$$

Esta imagem, embora, seja estruturada matematicamente, é também um outro tipo de representamen que, por sua vez, possibilita a criação de outros interpretantes, os quais também fazem nascer outros signos e, assim, sucessivamente. Porém o sentido desta equação somente pode ser dado pelo interpretante, que evoca outras representações para significar o objeto neurônio. A mesma coisa acontece com as palavras que, na maioria das vezes, são empregadas como simples etiquetas na atividade de representação indexal para representar conteúdos tratados em documentos verbais ou não verbais. Estas palavras, enquanto representamens dos objetos do mundo, também são signos que despertam ou afetam os interpretantes - idéia mental dos sujeitos - (que não são os intérpretes), fazendo nascer em seu espírito outros signos para dar sentido àquilo que estão percebendo não apenas com a imagem das palavras mas também com a idéia que elas transmitem. Em todos os casos, o signo faz referência ao objeto, portanto, tem relação com o mundo real, porém, como bem defende Peirce (CP2, p.243-253), "nunca na perspectiva unívoca, muito pelo contrario, sempre visando à representação de um signo mais evoluído" e isto está relacionado ao mundo simbólico dos sujeitos a partir dos interpretantes, enquanto idéia que toca os receptores na produção de sentidos. Com relação aos interpretantes, o autor distingue ao menos três tipos de interpretantes lógicos: a) imediato, considerado como sendo a expressão do signo no espírito do intérprete; b) dinâmico, considerado o efeito desenvolvido que produz o signo no intérprete; c) final, o efeito que o signo produziria caso fosse possível deslocar-se completamente do signo para atuar.

A partir da relação triádica (signo/objeto/interpretante) e visando a melhor compreensão destes tipos de signos, Peirce (CP2, p243-253) criou e organizou classes ou categorias em tricotomias. A primeira classe tricotômica tem relação direta com o representamen, sendo constituída pelas categorias de qualisigno, sinsigno e legisigno. Os qualisignos 
caracterizam-se por qualidade sígnica geral e imediata, o sinsigno corresponde à singularidade ou individualidade do signo e o légisignos (lei ou convenção) que supõe a idéia de universalização. A segunda tricotomia apresenta relação entre o representamen $e o$ objeto estando aqui inseridas as seguintes categorias de signos: ícone, índice e símbolo. $\mathrm{Na}$ visão peirciana esta tricotomia é a mais importante. A terceira tricotomia tem relação entre o signo ou representamen e seu interpretante e sua categoria é constituída pelo argumento, dicisigno(dicente) e rhema. $\mathrm{O}$ argumento é um signo no qual a interpretação se orienta a uma conexão sistemática, inferencial e legal com outros signos e no qual interpretante do argumento se constitui na conclusão enquanto produto do argumento. Na perspectiva de Peirce (CP2, p.310) o argumento "é um signo que, para seu interpretante, é um signo de lei". O signo dicisigno constitui-se de qualquer tipo de enunciados que conecta o sentido com o referente, porém, sempre demanda confirmação de veracidade por parte do interpretante. Peirce(CP2, p312) define um dicisigno "como um signo representado em seu interpretante significado como se fora uma Relação Real com seu Objeto". O rhema é um signo que se constitui de enunciados chamados de termos e cuja veracidade torna-se praticamente impossível de averiguação, salvo se em contexto.

Para o objetivo deste estudo, nos interessamos à segunda categoria tricotômica, mais precisamente o ícone. Segundo Peirce (CP2, p.247) um signo icônico se refere a seu objeto devido à semelhança com ele, ou seja, ele possui características próprias ao objeto mesmo, sendo exatamente igual, existindo ou não o objeto. Peirce lembra que se o objeto não existir, o ícone não age como signo, "mas, isto não tem nada a ver com seu caráter de signo. Não importa o que, qualidade, indivíduo existente ou lei, é o ícone de qualquer coisa, contanto que ele seja semelhante a esta coisa e seja usado como signo desta coisa".

Na perspectiva Peirciana, a imagem visual é uma sorte de ícone. Ora, se ela é a imagem do objeto, isto quer dizer que ela porta informações sobre este objeto, portanto, ela é um elemento de comunicação, pois, segundo Peirce (CP2, p.278), "[...] toda asserção deve conter um ícone ou um conjunto de ícones, ou ainda conter signos cuja significação não pode ser explicável a não ser através dos ícones". Por exemplo, quando vemos a fotografia de um coração, ela se parece com o coração cuja imagem temos em nosso espírito, quer dizer, ela conserva certas características do desenho do coração, de sua cor e de sua textura, que é o objeto representado. Na proposição Peirciana, os ícones se dividem em três tipos: as imagens, os diagramas e as metáforas. Aqueles que fazem parte de simples qualidades "[...] são as imagens; os que representam as relações, principalmente diádicas ou consideradas como tal, as partes de uma coisa pelas relações analógicas em suas próprias partes, são diagramas; aqueles que representam o caráter representativo de um representamen representando um paralelismo em qualquer coisa outra, são as metáforas" (PEIRCE, CP2, p.277). O índice é um signo que possui uma relação causal com seu objeto, não pela semelhança ou analogia, mas principalmente, porque ele tem uma relação física material (afeta diretamente), com a coisa ou objeto que ele designa, afetando-o diretamente. Peirce define o índice como sendo um signo que

"[...] se refere ao objeto que ele denota devido ao fato de ser realmente afetado pelo referido objeto [...]os índices podem ser distintos de outros signos ou de representações por três características: primeiro, eles não 
possuem alguma semelhança significativa com seus objetos; segundo, eles se referem a indivíduos, unidades singulares, coleções singulares de unidades, ou contínuos singulares; terceiro eles dirigem a atenção a seus objetos compulsão cega. [...]. Eles estão em conexão dinâmica com o objeto individual por um lado e com o senso ou a memória da pessoa para a qual ele serve de signo, por outra parte" ( PEIRCE, CP2, p.147, 248, 305)

Neste sentido, os índices são percebidos como sendo uma espécie de pista, avisos ou sintomas que possuem relação de contigüidade com a coisa manifesta (representamen) e seu objeto. Por exemplo, a imagem de um coração inchado é índice de doença, a fumaça é índice de fogo. Em que concerne aos símbolos, Peirce (CP2.292) diz que eles são [...] representamen cujo caráter representativo consiste precisamente em regras ou leis que determinam seu interpretante. Todas as palavras, frases, livros, e outros signos convencionais são símbolos". Em outras palavras, os símbolos são signos construídos de modo arbitrário ou convencional possuindo relações com as culturas, logo, a relação signo /objeto não é imediata, porque ele não tem semelhança ou contigüidade com o objeto. Por exemplo, a imagem de um coração em uma publicidade, pode ser símbolo de solidariedade, de amor a vida, de não a guerra.

Devido ao fato de que as imagens visuais se referem aos objetos do mundo real, podemos encontrar as três categorias peircianas de signos (ícone, índice ou símbolo). São estes elementos que permitem aos sujeitos construir as representações sobre o mundo, tendo conhecimento dele e também de se comunicar através dele. Esta é a perspectiva que interessa ao tratamento da informação contida nas imagens enquanto signos, quer dizer, nosso interesse é sobre a representação indexal destes documentos, aspectos que serão apresentados a seguir.

\subsection{Representação indexal: uma atividade cognitiva}

A representação indexal de textos verbais ou não verbais é uma atividade que, a despeito de sua acentuada dimensão prática, relaciona-se a processos cognitivos. Tratase de um fazer constituído por um conjunto de ações concernentes ao tratamento da informação contida nestes documentos, atribuindo-lhes etiquetas que possam representar o seu conteúdo, permitindo, não somente o acesso durante uma busca de informação em bases de dados, mas, também que o sujeito possa se deslocar sobre o documento mesmo, em sua natureza concreta, visando à recuperação posterior de seu conteúdo. A efetivação desta atividade envolve a leitura dos documentos seguindo-se a sua estrutura lógica ou física ou, ainda, segmentando-os em várias partes ou passagens para que possam ser identificados conceitos capazes de traduzir os assuntos ou temas neles tratados. Embora pareça simples, na realidade se trata de uma atividade complexa, visto que, em sua trama, estão envolvidas atividades de análise e síntese para a construção representacional dos conteúdos documentários. Esta atividade pode ser efetivada fazendo-se uso da linguagem natural ou controlada com o objetivo de traduzir os conteúdos dos documentos em "etiquetas" ou "index" indexais capazes de criarem no interpretante, enquanto signo, sentidos sobre os objetos do mundo para uma localização posterior de informação (Bentes Pinto, 2002).

Por que defendemos a indexação como um tipo particular de representação do conhecimento? Porque nesta atividade são construídas representações "mínimas"; os 
"indexes", referentes àquilo que se percebe do conteúdo dos documentos. Os referidos "indexes" são signos que vão, portanto, "estar no lugar" dos objetos que compõem os conteúdos dos referidos documentos, tanto para os que efetuam a atividade de indexação, como para aqueles que buscam encontrar informações, independentemente de espaço e tempo. Quando se realiza a atividade de representação indexal, na realidade, escolhem-se signos representados por termos, palavras-chave, descritores ou conceitos a fim de que eles possam substituir certos objetos aos quais não temos acesso, a não ser pelos discursos apresentados nos documentos mesmo. Assim, o "signo" ou "pista" nos remeterá a um interpretante (idéia) do objeto produzida pelo representamem. Então, mais uma vez, nos deparamos com a complexidade desta atividade, afinal, para construir a representação indexal de um único documento, pelo menos três atores entram em cena: o autor do documento, o indexador (humano ou não-humano) e o usuário, sendo que cada um destes tem percepção diferente sobre o conteúdo do documento. Por isso, a coincidência na definição das pistas de representação do conteúdo tratado, provavelmente não ocorrerá, mesmo que ingenuamente desejável. Ora, se um único ator não constrói única representação ao ler um mesmo documento em momentos distintos de sua vida, imagine-se três sujeitos. Isto vem ao encontro da "semiosis ilimitada", na qual os signos proporcionam o nascimento de outros signos que são mais evoluídos.

Os indexadores humanos estabelecem os "indexes" a partir da compreensão dos assuntos ou temas tratados nos documentos. Tal compreensão tanto pode ser influenciada pela sua bagagem cultural, como também pelo conhecimento que eles possuem sobre os tais assuntos ou temas. Os usuários utilizam esses "indexes", ou os seus "atalhos" enquanto representações que eles têm sobre as coisas ou sobre os objetos do mundo, visando o acesso às informações concernentes àquilo de que necessitam. Em quaisquer dos casos, temos a presença do conceito mais simples e mais conhecido de representação; "estar no lugar de..." e, naturalmente, a concepção semiótica peirciana de signo. O resultado é uma espécie de discurso e se constituem em documentos secundários a partir de pistas referentes ao conteúdo do documento primário que foi indexado. Eles são, portanto, representamen dos elementos que fazem parte do conteúdo do documento, enquanto objeto representado. Desse modo, o objetivo da representação indexal é construir "index" (etiquetas) indicando o conjunto de assuntos ou temas que foram tratados em um documento (verbal ou não verbal) os quais podem auxiliar àqueles que demandam informações nas bases de dados de sistemas de informação, ou mesmo na fonte primária. Na realidade, quando se fala em representação indexal, está-se falando de tratamento cognitivo da informação, uma vez que o ser humano, pela própria natureza, está sempre construindo pistas para encontrar informações. Contudo, nesta atividade não podemos nos esquecer de que o termo "index" não possui o mesmo sentido de índice proposto por Peirce, pois, neste ultimo, há uma relação sintomática causal com o objeto do mundo. Ao contrário, do "index", cuja relação é direta com a presença do objeto que ele faz referência, ou seja, eles enviam, antes, aos signos icônicos e aos símbolos. Os "indexes" são uma espécie de discursos construídos ou pelos humanos ou através dos softwares informáticos. Conforme o sentido da palavra, os "indexes" propõem-se a indicar ou apontar a direção que pode ser tomada com o objetivo de encontrar e ter acesso a informações. Entretanto, eles só podem ser considerados representações de conteúdos de documentos, se forem capazes de mobilizar, no sujeito intérprete, os significados do objeto, através da idéia 
que é o signo interpretante. Para ser signo, é necessário que tal "index" toque ou seja portador de sentido para os receptores que buscam informações em bases de dados tradicionais ou eletrônicas. Portanto, como qualquer outro signo, os chamados "indexes" têm sempre o objetivo de facilitar a comunicação entre o sujeito e seu meio ambiente, mesmo que nem sempre estes dispositivos sejam eficazes, uma vez que é o interpretante (idéia) construído na mente do sujeito receptor o responsável pela atribuição (ou não) do sentido relativo ao signo indexal. Com outras palavras, mesmo que o "index" corresponda a um signo de primeiridade, seu significado necessariamente não será unívoco, pois o interpretante enquanto idéia trabalha na perspectiva do mundo real e simbólico.

A história da representação indexal, no contexto das Ciências da Informação e da Biblioteconomia, nos mostra que o uso técnico deste termo aparece após a Segunda Guerra (1939-1945). Entretanto, a sua gênese significante remonta à Antiguidade, quando os primeiros homens construíram os desenhos nas cavernas e muros com uma estrutura lógica de representação do conhecimento visando à comunicação entre eles. Com os escribas apareceram os indexes dos textos verbais, que ficaram conhecidos pelo nome de "listas". Segundo Jean Bottéro (1987, p.68), essas "listas" são constituídas pelo conjunto de palavras,

[...] que foram cuidadosamente classificados, que puderam servir, primeiramente, de catálogos de caracteres, de mementos indispensáveis para aprender e dominar os elementos da escrita, mas cuja prática constante ulterior, nos ensina que elas tiveram por objetivo, em suma, classificar os objetos, de elaborar inventários ao mesmo tempo completos, tanto quanto possível, e, sobretudo, raciocinados, dos múltiplos sectores do mundo extra mental.

Sob o olhar de Jacob (1994, p.285-286) estas listas, (catálogos e "indexes") são ferramentas que podem contribuir como pistas para o acesso e a recuperação da informação, uma vez que elas compartilham características comuns se apresentando em uma série de nomes próprios ou mesmo de curtas proposições compostas sob o mesmo modelo.

[...] Este dispositivo é, sobretudo minemotécnico: ele agrupa em um suporte único informações dispersadas em outro lugar, impondo-lhes uma ordem [...]. Pode-se classificar, ordenar em categorias e tipos, hierarquizar, arranjar por ordem alfabética, ou mesmo fazer remissivas a outros livros, como os Pinakes de Calimacus na biblioteca de Alexandria. [...] O pinax se torna, por conseguinte, um modo particular de comunicação. Seu autor ocupa uma posição de mediador entre uma massa de informações disseminadas nos livros, portanto, a coleta e a síntese demandariam um longo trabalho, e um usuário potencial que beneficiará deste trabalho de compilação e de colocar em ordem. Este objeto traz, por conseguinte, tanto um saber como um serviço. Portanto, não se trata simplesmente de entesourar os conhecimentos, mas de torná-lo mais eficaz permitindo o controlo e a utilização de maneira econômica.

A aparição do termo indexação de imagens visuais acontece de modo similar tal que sucedeu com textos verbais. Isto é, as primeiras tentativas foram colocadas em prática por bibliotecários, arquivistas e historiadores, a partir do fim da Primeira Guerra (19141919), com o objetivo de facilita o acesso às coleções de fotografias que pertenciam às 
Universidades e aos museus (TURNER, 1994). Antes destas experiências e ainda nos dias atuais, as imagens foram e continuam praticamente ignoradas no tratamento da informação documentária, mesmo que elas fizessem ou façam parte do texto verbal, para ilustrar ou para esclarecer os assuntos neles tratados. Do ponto de vista teórico, podemos dizer que a representação indexal de imagens visuais, enquanto texto, é herdeira das grandes reflexões concernentes às teorias da linguagem. Segundo Meunier (1986) elas são oriundas ao menos de duas correntes de pensamento: a) a européia e continental, defendida, entre outras, por Bertin (1967), Marin (1972, 1973, 1978), o grupo $M u$ (1974) Bassy (1978), e que se apóia na tradição lingüística e retórica, cuja imagem visual é percebida "como uma língua, um texto e mesmo um discurso"; b) a britânica e americana, que "se inspira na tradição lógica" defendida, entre outros, por Beardsley (1958), Hospers (1946), Goodman (1968, 1978,), Black (1972), Margolis (1974), Sircello, (1972) e que se apóia na perspectiva lógico semântica. Nesta perspectiva a frase, é uma instância material no sentido de prova, exprimindo materialmente cada etapa de uma demonstração. Se, por exemplo, "ela é ausente em uma dedução, a prova não funciona". Então, fazendo uma analogia do quadro (pintura), Meunier(1986) diz que ele pode ser

$$
\begin{aligned}
& \text { [...] considerado como análogo de uma (grande) frase. Se ele é como } \\
& \text { pretendem os artistas um "statement", ele deve ter uma forma material } \\
& \text { própria, i. e., se apresentar em uma média particular e ocupar um } \\
& \text { espaço-tempo específico. Teoricamente, ele é também reprodutível. } \\
& \text { Com efeito, mesmo que habitualmente único, o quadro pode, em } \\
& \text { certos casos, ser reproduzido (artes gráficas, gravuras). Além do mais, } \\
& \text { ele pode ser visto como uma vasta argumentação onde cada um dos } \\
& \text { constituintes é concebido como um elemento contribuindo à } \\
& \text { demonstração (narração) geral querida pelo pintor. A semiologia } \\
& \text { pictorial contemporânea e iconográfica clássica procede assim: Ela } \\
& \text { identifica certo número de figuras, ícones, isotopias, junto às frases } \\
& \text { isoladas participando de maneira totalizante aos conjuntos de } \\
& \text { mensagens simbólicas da obra. Um quadro efetua assim, à sua } \\
& \text { maneira uma (de)monstração complexa. Ele é análogo de uma prova } \\
& \text { ao senso de uma seqüência ordenada de fórmulas ou de frases (um } \\
& \text { texto) ligado à uma finalidade demonstrativa. }
\end{aligned}
$$

A partir da proposição de Meunier, podemos dizer que outras imagens visuais também são grandes frases ou sentenças textuais. Elas têm uma forma material própria, e inclusive podem ser reproduzidas principalmente, com as tecnologias da informação cada vez mais modernas e possantes. Cada atributo visual das imagens funciona como linguagem para o receptor que constrói sentidos lendo os sintagmas simbólicos da obra.

Podemos dizer que foram quatro os paradigmas experimentados pela representação indexal das imagens: o primeiro diz respeito à indexação manual e em linguagem natural, tomando por base o modelo da análise de imagem construído por Ervin Panofisky (1955). Nele, consideram-se os níveis pré-iconográfico, iconográfico e iconológico, cuja estrutura contém as seguintes questões: quem, onde, quando, o que e como. O segundo momento é o da indexação assistida, (semi-automática, ou da indexação de imagem por conceitos, descritores). É o paradigma da indexação controlada, onde os "indexes" são atribuídas a partir das linguagens documentária do tipo thesaurus ou classificações para representar os assuntos percebidos nas imagens pelos indexadores, sejam eles humanos ou não. O terceiro refere-se à indexação por 
conteúdo ou atributos visuais das imagens (cor, textura, forma), e podemos chamar indexação sintática ou "full imagem" totalmente automática. O quarto é o da indexação mista ou semântica, que utiliza tanto os atributos visuais da imagem, como as palavras para estabelecer o sentido nas representações destes documentos. Estes quatro paradigmas nos permitem inferir que a representação indexal de imagens pode assumir, pelo menos, três hipóteses: a) teleológica, cujo tratamento da imagem atende a uma finalidade especifica (CLEMENT, THONNAT, 1993; CLOUARD et al., 1999); b) semiótica/ontológica, na qual a imagem é tratada como signo, cuja representação indexal pode ser feita através da descrição física da imagem como um todo, ou a partir dos objetos que compõem a imagem, a relação entre eles, e a compreensão semântica dos objetos da imagem (PEIRCE, 1978; ECO, 1992; JOLY, 1994); c) fenomenológica, na qual o tratamento da imagem volta-se para a descrição dos objetos ou fenômenos perceptíveis em superfície (TSOTSOS, 1992).

A) O paradigma da representação indexal de imagens em linguagem natural

Este paradigma emergiu por volta dos anos setenta do século $\mathrm{XX}$, cujas experiências foram apoiadas no modelo de análise de imagem construído por Ervin Panofsky (1955), o qual leva em consideração as categorias pré-iconográficas, iconográficas e iconológicas. Tomando por base a proposta de Panofsky, Ginette Blery (1976) criou um modelo de indexação de imagens a partir das seguintes facetas: objetos (quem), lugar (onde), tempo e espaço (quando), atividades e acontecimento (o que), e modos (como). Tal modelo foi utilizado também por Shatford (1986) e Johanna Smit (1996), onde as facetas antes referidas dialogam com aquelas apresentadas por Corinne Jörgensen (1996) sob as denominações de atributos perceptíveis, interpretativos e reativos diante da imagem. Os primeiros (perceptíveis) respondem diretamente a estímulos visuais, como por exemplo, a cor, a textura, a forma e os próprios objetos componentes da imagem. Os segundos (interpretativos) são aqueles que exigem do analista a aplicação de um nível de conhecimento geral sobre a imagem, além da capacidade para inferir sobre o estilo e o modelo quando se tratarem de representações imagéticas relativas a peças ou objetos de arte. Os terceiros (reativos) referem-se às sensações provocadas naquele que vê ou analisa o conjunto dos signos que concorrem para a constituição da imagem. A esse respeito, podemos evocar, mais uma vez, a noção peirciana de semiosis ilimitada, decorrente da fusão dos atributos aqui mencionados, presentes nas diferentes formas de percepção dos sujeitos.

A representação indexal de imagens em linguagem natural é uma prática livre, feita de maneira totalmente manual, caracterizada por inúmeros problemas. Todavia, não podemos nos esquecer de que estas dificuldades são próprias do campo das representações, sejam elas visuais, mentais, ou realizadas com o emprego de tecnologias sofisticadas, pois falar de representação é mexer sempre com questões de natureza simbólica e subjetiva. Então, mesmo que os indexadores estabeleçam a maior exaustividade representacional através de indexes de palavras, eles jamais terão $100 \%$ de eficácia nas respostas demandadas pelos usuários, uma vez que, conforme já mencionado anteriormente, o sujeito tem sempre suas próprias maneiras de perceber e nomear as coisas e os objetos do mundo. Corroborando, Turner (1994) acentua que única imagem pode aportar vários e diferentes significados tanto para uma mesma 
pessoa, como para diferentes pessoas, segundo o objetivo de sua utilização, o momento em que elas são utilizadas e em razão da dinamicidade das palavras tanto selecionadas pelos indexadores durante a atividade de indexação como pelos usuários durante a busca de imagens. Outra dificuldade apontada por Graham (2001, p. 24-25) a esse respeito, refere-se ao ponto de vista do indexador que nem sempre coincide com aquele do usuário. É o caso de uma indexação sofisticada para usuários pouco especializados. Ao contrário, quando o usuário é um especialista do domínio da imagem solicitada e a encontra indexada sob uma forma muito singela de representação. Ressaltamos ainda que a polissemia da própria imagem também contribui para aumentar as dificuldades na atividade de representação indexal destas fontes informacionais, seja em relação a elas mesmas, ou pelas palavras escolhidas para representar o conteúdo imagético.

Buscando alguma forma de ancoragem empírica para as reflexões que estamos desenvolvendo, realizamos uma pesquisa sobre imagem em 200 páginas abrigadas no sistema Web, tendo como finalidade recuperar documentos que se reportassem ao termo "coração", porém sem fazermos qualquer tipo de predicação capaz de identificar a natureza da demanda. Conforme podemos observar nos objetos constantes da figura 4, as respostas obtidas apresentaram elevado índice de revocação, ou ruído, para empregar outra expressão muito presente na literatura relativa à área da informação.

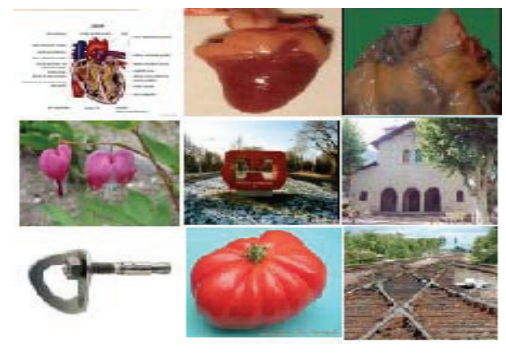

Fig. 4- Resultado da busca de imagens a partir da palavra "coração" Fonte : http://www.google.com/

Todos estes aspectos relacionados com a multiplicidade de sentidos evocados nas imagens fazem parte tanto das atividades práticas (indexadores e usuários), quanto das reflexões teóricas (pesquisadores, especialistas). É que estes documentos de mesmo que as palavras, são, pela própria natureza, obras abertas, polifônicas, fato que torna difícil a construção de sua representação indexal com menos polissemia.

B) O paradigma da representação indexal de imagens por conceito

Em razão das dificuldades apresentadas no item anterior, surgiram outras proposições de indexação de imagens visuais, não mais através de termos livremente estabelecidos por indexadores, em linguagem natural, mas adotando-se a estratégia de uma linguagem controlada. Para isto, bibliotecários, e outros especialistas, criaram linguagens documentárias ou controladas do tipo classificação, cabeçalhos de assuntos e tesauros como possíveis formas de reduzir as ambigüidades inerentes à linguagem natural. Assim, foram colocados em prática, entre outros, os "thesaurus based indexing systems". Esta nova maneira de indexar pode permitir o controle das polissemias das palavras, não somente durante as atividades de indexação, mas também na recuperação 
da informação. Contudo, convém repetir, que tal controle pode não passar, às vezes, de uma simples minimização, afinal de contas, o ser humano constrói suas próprias etnografias (mesmo de modo inconsciente) quando busca informações em bases de dados, ainda que os gestores destes recursos tracem caminhos a serem seguidas pelos usuários durante a "garimpagem das imagens" nos sistemas de recuperação de informação (sri). Entre os "thesaurus based indexing systems", destacam-se o Iconclass, Art \& Architecture Thesaurus e o Thesaurus for Graphic Materials (TGM). Na figura5, apresentamos um exemplo de representação indexal utilizando este ultimo tesauro.

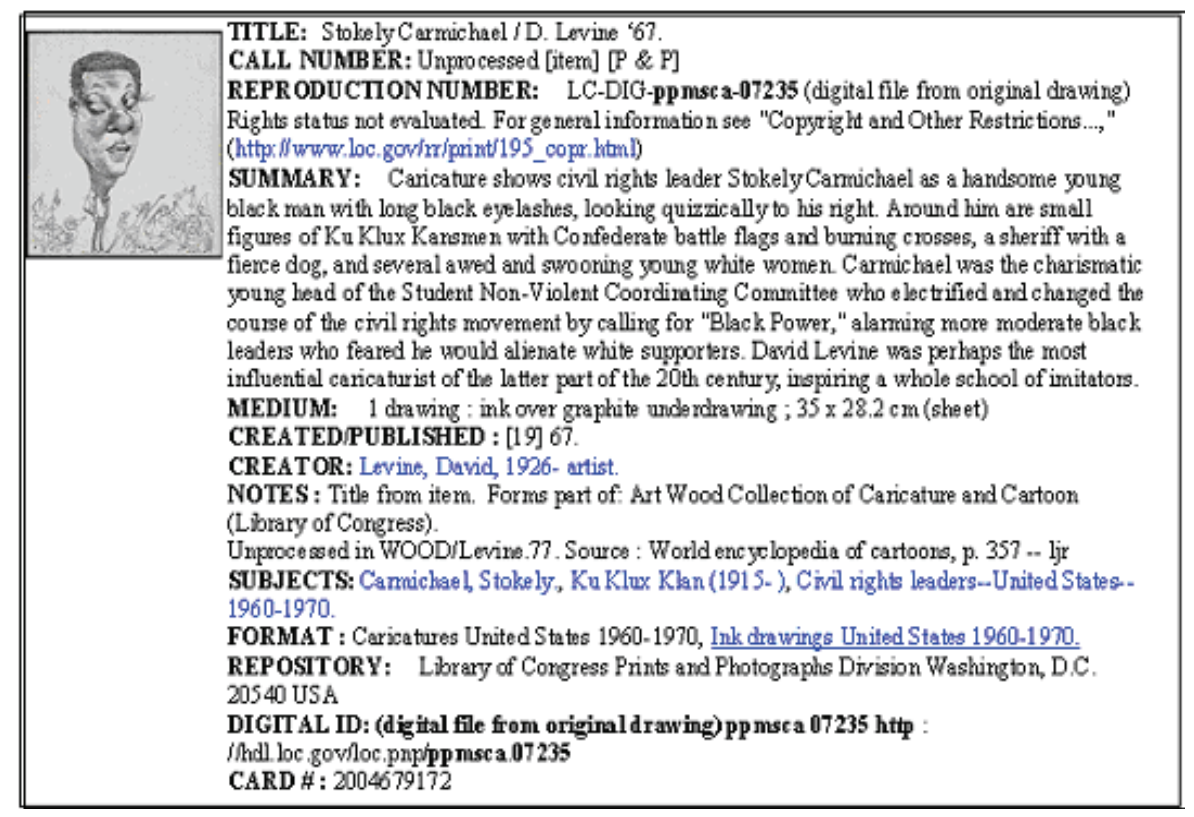

Fig.5-Resultado da busca sobre o TGM

Fonte : Prints \& Photographs Online Catalog (PPOC).

O uso destas ferramentas foi alvo de várias críticas por parte dos usuários, pois, como bem argumenta Hogan et. al. (1991, p. 205)

[....] In the case of images, the use of thesauri to control inconsistency is not effective due to the individual responses prevalent in human reactions to visual materials. That inconsistency is a reflection of creativity and diversity of human interests, situations, and context. If inconsistency is to be overcome, system designers will need to relinquish the idea of the utility of using words to index nonverbal understanding...We are looking for alternative ways of image retrieval, ways that are less dependent on familiarity with existing taxonomies and their assigned authorities.

Na realidade, a questão que se põe é, como representar por meio de palavras, detalhes bem precisos dos componentes formais das imagens visuais como, por exemplo, a combinação de cores, atitudes e gestos? Como representar detalhes anatômicos, sentimentos expressos em uma imagem visual etc.? De acordo com Rui et. al. (1999), existem duas grandes dificuldades para o tratamento manual ou semi-automático de imagens visuais: a primeira diz respeito ao tamanho das coleções de imagens e a complexidade do trabalho demandado para descrever manualmente as imagens. A segunda se refere à riqueza de conteúdos registrados nas imagens e da subjetividade humana de percepção desses conteúdos. 


\section{C) O paradigma da representação indexal por conteúdo sintáxico}

Depois de apresentadas as dificuldades na representação indexal de imagens somente por palavras (termos, descritores), em razão do aumento das imagens digitais originais e escaneadas, devido a ineficácia das respostas às buscas de imagens em bases de dados, assim como do avanço das pesquisas interdisciplinares (teóricas e aplicadas), foram propostas outras formas de indexar e de buscar imagens. Desta feita, pelo conteúdo. Para tal, foram construídos os Content-Based Image Retrieval (CBIR), capazes de estabelecer automaticamente a representação indexal de imagens levando em conta toda a superfície da imagem, a partir de seus atributos visuais, por exemplo, cor, textura, forma e luminosidade. Em lugar das palavras, sempre utilizadas em sistemas tradicionais e também nos sistemas baseados em linguagem controlada, para se estabelecer a representação indexal e para a recuperação da informação, neste novo paradigma esta representação se efetua pelos componentes visuais da imagem. Segundo Vailaya e Zhang (1998), os atributos visuais das imagens podem ser classificados em "geral" e "específicos". Os primeiros contemplam as cores, as texturas e as formas das imagens, enquanto que os segundos ou específicos, levam em conta somente os aspectos particulares; por exemplo, um rosto, um dedo, um dente, uma assinatura. Tais atributos podem ser empregados em um domínio particular bem específico como é o caso das áreas de saúde, gestão bancária, polícia e arquitetura.

As primeiras experiências com o uso do CBIR foram feitas por Toichi Kato (1992) em uma coleção do Art Museum. Seu objetivo foi a representação e a recuperação automática de imagens contidas nas bases de dados, tomando como atributos a cor e o contorno. Os sistemas CBIR oferecem paletas contendo três (3) cores tradicionais comuns; vermelho, verde e azul conhecidas como red,green,blue (RGB). Além das cores, o CBIR também pode oferecer paletas de forma ou de textura. Nestas paletas os indexadores e usuários podem escolher as cores, as formas e as texturas que sabem ou acreditam estar presentes na imagem combinando-as na forma de discursos (index de cores, texturas ou formas em lugar das palavras), para que possam indexar e recuperar a imagem. Feito isto, as ferramentas do CBIR os traduz em seqüências de vetores de intensidades de pixeles numéricas, cujo objetivo é de representar o conteúdo de uma entidade e de fornecer informações. A utilização dos vetores se explica, pois, normalmente, o tamanho das imagens é muito grande e isto contribui para aumentar as dificuldades para lhes indexar automaticamente somente pelos atributos mencionados. Através destes vetores, o CBIR busca extrair as informações das imagens a fim de caracterizar seu conteúdo global ou particular. Após esse primeiro tratamento, as imagens são matematicamente estruturadas e comparadas entre elas para se avaliar suas semelhanças visuais quando das buscas em coleções de imagens. Para exemplificar o uso dos atributos visuais da imagem, no processo de recuperação indexal por conteúdo, fizemos algumas experimentações utilizando o sistema QBIC da IBM, que usa a tecnologia CBIR. Para isto efetuamos uma visita virtual ao Museu Hermitage localizado na cidade de "San Petesburgo" (www.hermitagemuseum.org/). Escolhemos como assunto de busca, as imagens do arco-íris. Tomando como modelo as paletas de cores constituídas por um conjunto de cinco (5) cores, selecionamos aquelas que poderiam representar o arco-íris. Obtivemos como respostas, 14 imagens, porém, nenhuma se mostrou pertinente para nossa pesquisa. A imagem mais próxima de nossa demanda foi a obra do artista russo Vasily Kandinsky denominada View of Munuau e que por acaso 
trazia dentre as cores utilizadas pelo artista, algumas relativas aquelas do arco-íris, como pode ser observado na figura- 6 .

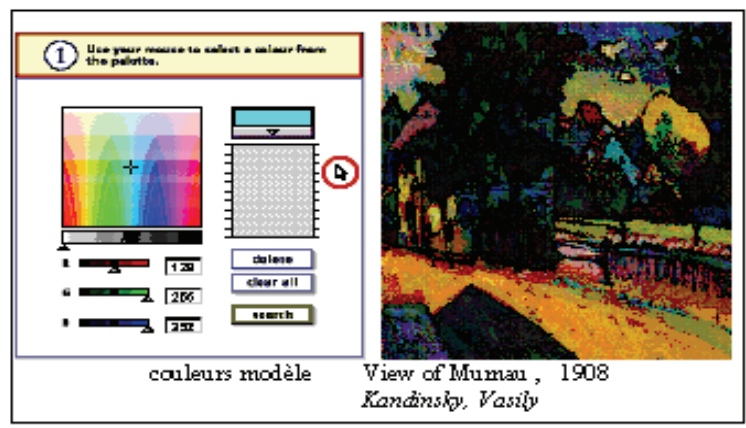

Fig. 6-Modelo de cores do QBIC

Fonte : Muséum Hermitage - www.hermitagemuseum.org/

Observando esta imagem, constata-se que as respostas não foram eficazes. A revocação dos resultados pode ser em conseqüência de que a indexação foi feita tendo por base as combinações das cores oferecidas pela paleta e que são ineficazes para descrever as cores do arco-íris que são bem diferentes daquelas oferecidas pela paleta do QBIC. Além do mais, as cores oferecidas para as buscas são limitadas; uma vez que neste sistema somente podemos escolher a combinação de cinco cores e, na realidade, ao se mirar o arco-íris percebe-se que ele possui sete cores.

Em uma segunda experiência, utilizamos como estratégia de busca a forma. Para tanto, desenhamos na paleta do QBIC, um jarro com flores. Desta feita obtivemos 12 repostas, porém, somente uma (1) foi eficaz, figura-7. O ruído desta busca pode ser decorrente, entre outras coisas, da nossa falta de habilidades para exprimir com desenvoltura, as formas dos desenhos sobre a imagem que necessitamos.

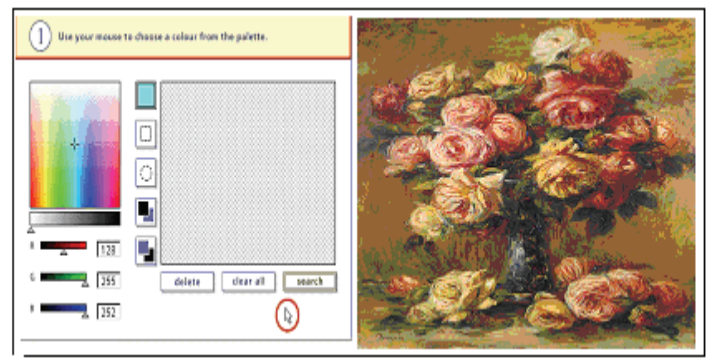

Fi.g-7 Rose in a Vase- Renoir, Pierre-Auguste -1910/1917 Fonte : www.hermitagemuseum.org/

Avaliando a eficácia do uso dos sistemas CBIR para indexação e recuperação de imagens, Armitage e Enser (1997) assinalam que as falhas dos primeiros sistemas decorrem em razão de que eles somente utilizaram atributos visuais para a representação indexal e a recuperação de informação. Então o grande problema decorre da distância entre o que as tecnologias oferecem e as necessidades de informação dos usuários. Para esses autores "[...] The vast majority of users do not want to retrieve images simply on the basis of similarity of appearance. They need to be able to locate pictures of a particular type (or individual instance) of object, phenomenon, or event". Corroborando, Eakins e Graham (1999, p.8) enfatizam que 
The effectiveness of all current CBIR systems is inherently limited by the fact that they can operate only at the primitive feature level. None of them can search effectively for, say, a photo of a dog - though some semantic queries can be handled by specifying them in terms of primitives. A beach scene, for example, can be retrieved by specifying large areas of blue at the top of the image, and yellow at the bottom. There is evidence that combining primitive image features with text keywords or hyperlinks can overcome some of these problems, though little is known about how such features can best be combined for retrieval.

Além do mais, a complexidade para se estabelecer a representação indexal de imagens baseada apenas nos atributos visuais reside, exatamente, na escolha dos referidos atributos, pois, como assinala Angheben et al. (2005) o conteúdo de uma imagem é portador de uma semântica bastante diferente e, naturalmente, varia

[...] segundo o observador (grande público, amador ou especialista) e além do mais independentemente da língua dos usuários. (...) as dificuldades científicas ocorrem na recomposição da informação de alto nível inclusa na imagem e descrita pela semântica associada. Esta recomposição resulta de duas operações, a primeira fase da decomposição (segmentação) e a segunda de refinamento da decomposição.

Ora, quando se trata textos verbais estamos diante de palavras ou conjuntos de palavras que são estruturadas logicamente para lhes fornecer sentido. Então, pode-se dizer que, efetivamente, nesses textos se têm uma evidência de organização semântica, estabelecida pelo autor, mesmo que, efetivamente, o sentido do consumo seja dado pelo receptor. Com o texto não verbal (imagem ou som) isto não acontece de forma evidente, daí a complexidade no tratamento informacional destes documentos. Estudando a semântica das imagens, Stéphane Bissol (2005, p. 20-21) mostrou cinco categorias de conhecimentos que podem ser observadas quando da representação indexal e recuperação de imagens visuais, quais sejam: conhecimento sobre a aparência visual do objeto, conhecimento específico sobre a aparência do objeto, conhecimento sobre as relações entre os objetos, conhecimento sobre as relações entre as instâncias específicas dos objetos contidos nas imagens, e uma cena determinada, além de outros conhecimentos não visuais (subjetivos) sobre os objetos em si. Todas essas categorias podem ser responsáveis pelo aumento do silêncio ou do ruído na representação indexal e na recuperação de informações registradas em imagens visuais, pois, nosso ângulo de percepção visual é ligado às nossas "leituras de mundo". Portanto, ele não é excluído de nossas crenças, de nossas concepções de mundo e evidentemente de nossa cultura, daí o porquê das dificuldades para se efetuar o tratamento de informações de documentos imagéticos.

Na realidade, nos primeiros CBIR assim como ainda em alguns contemporâneos, a proposição de representação indexal e de recuperação de informação percebe as imagens visuais como sendo "objetos fechados" e, isto contribui para aumentar o "fosso ou gap semântico" da imagem. De acordo com Smeulders et al. 2000) "the semantic gap is the lack of coincidence between the information that one can extract from the visual data and the interpretation that the same data have for a user in a given situation". Esta passagem vem ao encontro de inúmeras pesquisas mostrando que somente o uso de atributos visuais para a representação indexal e a recuperação de informações de documentos imagéticos não é suficiente e muito menos eficaz, pois, como foi dito 
acima, a exemplo dos textos verbais, as imagens são igualmente, ou quem sabe, muito mais polissêmicas do que aqueles.

C) O paradigma da representação indexal de imagens por conteúdo morfossemântico

A partir das experiências com a tecnologia CBIR e das dificuldades encontradas para estabelecer uma representação indexal eficaz de imagens visuais, os pesquisadores e conceptores de softwares desenvolveram outros sistemas mais performantes, cujo objetivo é entre outros, a indexação morfossemântica de imagens, também chamada mista ou indexação e recuperação de informação por conteúdo semântico. Nessa nova possibilidade, são levados em consideração, além dos atributos visuais de cor, forma, textura etc., os descritores dos tesauros, das listas de autoridades, das ontologias, ou ainda, os termos da linguagem natural. Quer dizer, essas proposições associam os textos verbais e os não verbais a fim de obter uma indexação e uma recuperação de informação imagética híbrida, com objetivo de obter melhores resultados. Com efeito, trata-se de uma aliança entre os critérios adotados pelos CBIR com as palavras, visando a construir uma representação indexal de imagens com melhor qualidade, uma vez que ela se apóia em dois atributos: os visuais - enquanto textos não verbais - e os textos verbais, pois somente os atributos visuais de cor, forma e textura ou os atributos verbais podem não ser suficientes para fornecer uma representação indexal com maior qualidade. Já existem na internet alguns sistemas comerciais e experimentais para a representação indexal de imagens visuais que adotam essa nova possibilidade. Para ilustrar esse paradigma, analisamos alguns sistemas, dentre os quais destacamos: Colour Hierarchical Representation Oriented Management Architecture (CHROMA), VIRImage Search Engine, ImageMedia e o próprio QBIC. A titulo de exemplo para este trabalho, realizamos mais uma vez a nossa experimentação no sistema QBIC, através do uso do sintagma "arco-íris", fazendo a busca no tesouro do Museu Hermitage e que adota o QBIC para o tratamento e a recuperação de imagens. Com essa estratégia lançamos a pesquisa e obtivemos 30 páginas com mais de 50 imagens, sendo que deste total 30 trouxeram em seu texto a palavra arco-íris referente a imagem do objeto mesmo (Figura-8). Ou seja, o uso da palavra associada aos atributos visuais da imagem foi bem mais eficaz para a sua recuperação.

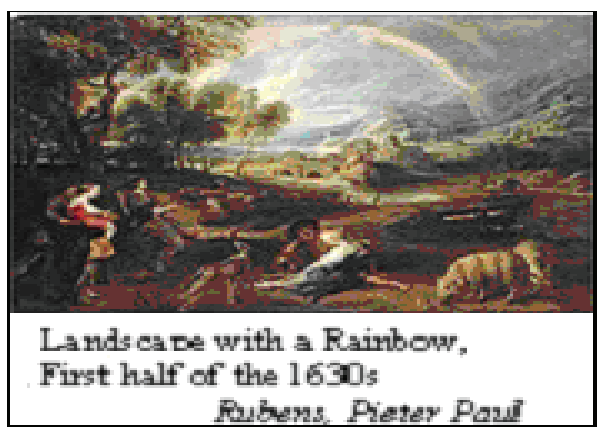

Fig.8-Busca por combinação de descritores e atributos visuais Fonte : www.hermitagemuseum.org/ 


\section{CONSIDERAÇÕES FINAIS}

Ao final das reflexões aqui desenvolvidas, podemos extrair algumas observações conclusivas em relação ao que concerne à importância das imagens na sociedade contemporânea, assim como sobre o que se refere aos paradigmas de sua representação indexal. Sendo assim, ratificamos que as imagens sempre se destacaram ao longo da história como fontes de informação, comunicação e preservação da memória. Com as modernas ferramentas tecnológicas, cada vez mais, elas são percebidas como ricas fontes de conhecimentos que podem ser produzias e empregadas em vários campos de saberes e em diferentes situações. Por exemplo, no campo cientifico técnico e artístico.

No que diz respeito ao paradigma do tratamento informacional de imagens visuais, particularmente no que se refere à sua representação indexal e recuperação de informação, podemos dizer que foram vivenciados quatro momentos: a) representação indexal manual, feito através de palavras oriundas da linguagem natural, ou seja, utilizando-se vocabulário livre; b) representação indexal semi-automática, utilizando-se vocabulários controlados, retirados dos tesauros e listas de autoridades, assim como de sistemas de classificação; c) representação indexal automática ou de conteúdo sintáxico, no qual as imagens são indexadas por meio dos atributos visuais de cores, forma, textura etc., e adotando-se os sistemas CBIR; d) representação indexal mista ou por conteúdo morfossemântico, se combinado atributos visuais com os descritores das linguagens controladas ou ainda com termos da linguagem natural, a partir das inovações dos sistemas CBIR.

Os resultados de pesquisas têm mostrado que o tratamento e recuperação de informações de documentos imagéticos baseados em palavras chave e atributos visuais podem oferecer respostas mais eficazes. No caso das palavras, elas podem ser utilizadas para descrever os objetos perceptíveis na imagem, porém, é praticamente impossível de decrescer com palavras sentimentos ou outros aspectos subjetivos das imagens. Na realidade, é impossível que se saiba realmente o que está por trás da criação de uma imagem visual, seja ela fotografia, quadro, desenho ou outra imagem, pois, enquanto representação de uma realidade, tanto quanto os textos verbais, elas são discursos construídos por seus criadores, então aí está a grande dificuldade para um indexador ou um usuário estabelecer as representações de conteúdos informacionais conferindo-lhes significados ou sentidos para as buscas destas ricas fontes de informação.

Entendemos que a apropriação do conceito semiótico peirciano de signo como representação traz grande contribuição para se realizar a atividade de representação indexação de imagens visuais enquanto atividade cognitiva, uma vez que esta proposta contempla o aspecto da semântica, através da presença do interpretante que, como idéia, produz sentido ao tratamento informacional da imagem enquanto texto não verbal.

Finalmente, se faz necessário ter consciência de que, como qualquer texto verbal as imagens visuais também merecem ser tratadas e representadas indexalmente, porém, de forma diferente daquele, a fim de que se possa ter alguma pista para se aceder ao seu conteúdo durante as buscas de informação. As estatísticas mostram que no espaço cyber existem centenas de milhares de imagens eletrônicas (originais ou cópias) e, cada dia é produzido muito mais. Ou seja, a cultura da imagem está ai, não é mais possível ignorá- 
la de nosso cotidiano, seja como usuários ou indexadores. Ora, são inúmeros os indivíduos que têm necessidades de utilizar essas fontes de informação para colocar em prática suas atividades, portanto, é necessário compreender a linguagem das imagens, para poder construir sua representação indexal visando a comunicação com elas e através delas.

\section{BIBLIOGRAFIA CONSULTADA}

ANGHEBEN, M. et. al. Images médiévales et nouvelles technologies de l'information : lecture d'images et indexation par le contenu. Le Médiéviste et l'ordinateur, 2005. Disponible sur : $<$ http://lemo.irht.cnrs.fr/varia/images-ntic.htm. Consulte 07/02/2006 $>$ Acesso em 16.01.2006

AUMONT, J. L'image. Paris :Nathan, 1990, 248 p.

ARMITAGE, L; ENSER, P G B. Analysis of user need in image archives. Journal of Information Science, v.23, n. 4, p. 287-299, 1997

ART \& Architecture Thesaurus (AAT). Disponivel em $<$ www.getty.edu/research/conducting research/vocabularies/aat/ $>$ Acesso em $10 / 01 / 2006$

BARBOZA, P. Les nouvelles images: Paris: Éditions d'art Somogy, Cité des Sciences et de l'Industrie, 1997.

BENTES PINTO, V. MEUNIER, J.-G. Les images visuelles en tant que sources d'information. Montreal, 2006. Relatório (Estagio Pos -Doutoral Universite du Quebec 'a Montreal).

BENTES PINTO, V.Representação do Conhecimento em Ciência da Informação através de Esquemas de Tarefa (ETAF) In: AQUINO, M. O Campo da ciência da informação. João Pessoa : UFPB, 2002

BISSOL, S. Indexation symbolique d'images : une approche basée sur l'apprentissage non supervisé de régularités. THESE (DOCTORAT DE L'UNIVERSITE JOSEPH FOURIER - GRENOBLE 1 Discipline : Informatique) 2005.

BLERY, Ginette. La mémoire photographique : étude de la classification des images et analyse de leur contenu à l'aide de l'informatique.Strasburg : S.Ed.1976

BOTTERO, J. Mésopotamie: l'écriture, la raison et les dieux.- Paris: Editions Gallimard, 1987.- 552p

CLEMENT, V., THONNAT, M. A knowledge-based approach to integration of image procedures processing. CVGIP: Image Understanding, v.57, n.2, p.166.184, Mar, 1993.

CLOUARD, R.; et. al. A knowledge-based system for automatic generation of image processing programs. IEEE Trans. on Pattern Analysis and Machine Intelligence, v.21, n.2, p.128.144, 1999.

EAKINS, J. P.; GRAHAM, M. E . Content-based image retrieval. (A report to the JISC Technology Applications Programme). Newcastle upon Tyne, United Kingdom: University of Northumbria at Newcastle, Institute for Image Data Research. 1999.

ECO, U. Le signe. Paris : Nathan, 1992.

EDELINE, F.; Klinkenberg, J.-M ; Minguet, P. Traité du Signe Visuel: pour une rhétoriqué de uma image. Paris: De Seuil. 1992. 
GRAHAM, M. E. The cataloguing and indexing of images: time for a new paradigm. Art Libraries Journal v.26, n.1, p.22-27, 2001

HOGAN, et. al. The visual thesaurus in a hypermedia environment: a preliminary exploration of conceptual issues and applications. In: INTERNATIONAL CONFERENCE ON HYPERMEDIA AND INTERACTIVITY IN MUSEUMS, 16, 1991, Pittsburgh-PA, Proceedings:... Pittsburgh-PA ,1991, p.202-221.

IBM. Query By Image Content System (QBIC). Disponível em < www.qbic.almaden.ibm.com> Consultado em 20/10/2005

ICONCLASS. Disponível em $<$ www.niwi.knaw.nl/en/geschiedenis/projecten/ iconclass/ Acesso em 20/09/2005.

JACOB, C. Inscrire la terre habitée sur une tablette. In : DETIENNE, M. Les savoirs de l'écriture en Grèce ancienne.Lilles : Presses Universitaires de Lille, 1988.- p.273-304.

JOLY, M. Image et les signes. Paris: Nathan, 1994

JÖRGENSEN, C. Indexing Images: Testing an Image Description Template. < http://www.asis.org/annual-96/ElectronicProceedings/jorgensen.html. Acesso em $20 / 08 / 2005$

KATO, T. Database architecture for content-based image retrieval. In: INTERNATIONAL SOCIETY OF OPTICAL ENGINEERING, 3846, 1992, New York, Proceedings....New York, 1992, 112-123.

MEUNIER, J.-G. La représentation en sciences cognitives. Compendiun de recherche et d'éssais, septembre 2002.

PANOFSKY, Erwin. Meaning in the visual arts. New York: Doubleday , 1955

PEIRCE, C. S. Collected Papers of C. S.Peirce ed. by C. Hartshorne, P. Weiss, \& A. BURKS, Harvard University Press, Cambridge, MA, 1931-1958. CP2, CP5, CP7.

PEIRCE, C. S. Écrits sur le signe. Paris :Seuil, 1978.

PEIRCE, C. S. Semiótica. São Paulo : Perspectiva, 1999.

RUI, Y.; Huang, T. S.; Chang, S.-F. Image retrieval: current techniques, promising, directions, and open issues. Journal of Visual Communications and Image Representation, v.10, p. 39-62, 1999

SANTAELLA, L.; NÖTH, W. Imagem: Cognição, semiótica, mídia. São Paulo : Iluminuras, 1999.

SHATFORD, S.Analyzing the subject of a picture: a theoretical approach. Cataloging \& Classifcation Quarterly, v. 6, n. 3 p. 39-62, Spring, 1986

SMEULDERS, A.; WORRING, M.; SANTINI, S.; GUPTA, A. Content based image retrieval at the end of the early years. IEEE Transactions on Pattern Analysis and Machine Intelligence, v. 22, n. 12, p.1349-1380, 2000.

SMIT, Johanna W. A representação da imagem. Informare: Cadernos do Programa de Pós-Graduação em Ciência da Informação, Rio de janeiro, v. 2, n. 2, 1996, p. 28-36.

TSOTSOS, J.K. On the relative complexity of active vs. passive visual search. International Journal ofComputerVision, v.7, n.2, p.127.141,1992.

TURNER, J. Indexing " Ordinary " Pictures for Storage and Retrieval. Visual Resources, v. X, p. 265-273, 1994

VAILAYA, J. A; ZHANG, H. On image classification: city images vs landscapes. Pattern recognition, v.31, n.12, p.1921-1936, 1998.

VIRAGE Inc. VIR Image Search Engine. Disponível em http://www.virage.com/products/vir-irw.html. Consultado em 19/08/2005 


\begin{abstract}
However, even if along history the visual images have gained a great importance as sources of information, one cannot deny that with the newest information and communication technologies (ICT) they drew the attention of experts from the most different fields of knowledge, such as arts, biology, astronomy, archeology, history, health, fashion, decoration, public relations, editing, engineering and architecture, among others. Presents some theoretical reflections concerning representation in Peirce's perspective based on the context of the new approaches used for the treatment of visual images, using as examples the paradigms of the manual, semiautomatic, automatic and mixed index representation. The results of the experiments show that the difficulties found in the construction of an index representation of that document type originate from the complexity inherent in the process of production and reception of the imagetic sign.
\end{abstract}

KEYWORDS: Image. Image indexing representation. Image representation .

Originais recebidos em: 19/10/2007

Texto aprovado em: ../03/2008 